\title{
Measuring atmospheric naphthalene with laser-induced fluorescence
}

\author{
M. Martinez ${ }^{1,2}$, H. Harder ${ }^{1,2}$, X. Ren ${ }^{1}$, R. L. Lesher ${ }^{1}$, and W. H. Brune ${ }^{1}$ \\ ${ }^{1}$ Department of Meteorology, Pennsylvania State University, University Park, Pennsylvania, USA \\ ${ }^{2}$ now at: Max-Planck-Institut für Chemie, Mainz, Germany
}

Received: 9 December 2003 - Published in Atmos. Chem. Phys. Discuss.: 19 January 2004

Revised: 24 March 2004 - Accepted: 29 March 2004 - Published: 4 April 2004

\begin{abstract}
A new method for measuring gas-phase naphthalene in the atmosphere is based on laser-induced fluorescence at low pressure. The fluorescence spectrum of naphthalene near $308 \mathrm{~nm}$ was identified. Naphthalene fluorescence quenching by $\mathrm{N}_{2}, \mathrm{O}_{2}$ and $\mathrm{H}_{2} \mathrm{O}$ was investigated in the laboratory. No significant quenching was found for $\mathrm{H}_{2} \mathrm{O}$ with mixing ratio up to $2.5 \%$. The quenching rate of naphthalene fluorescence is $(1.98 \pm 0.18) \times 10^{-11} \mathrm{~cm}^{3}$ molecule $\mathrm{e}^{-1} \mathrm{~s}^{-1}$ for $\mathrm{N}_{2}$, and $(2.48 \pm 0.08) \times 10^{-10} \mathrm{~cm}^{3}$ molecule ${ }^{-1} \mathrm{~s}^{-1}$ for $\mathrm{O}_{2}$ at $297 \mathrm{~K}$. Instrument calibrations were performed with a range of naphthalene mixing ratios between 5 and 80 parts per billion by volume (ppbv, $10^{-9}$ ). In the current instrument configuration, the detection limit is estimated to be about 20 parts per trillion by volume (pptv, $10^{-12}$ ) with $2 \sigma$ confidence and a 1-min integration time. Measurements of atmospheric naphthalene in three cities, Nashville, TN, Houston, TX, and New York City, NY, are presented. Good correlation between naphthalene and major anthropogenic pollutants is found.
\end{abstract}

\section{Introduction}

Polycyclic aromatic hydrocarbons (PAHs) are composed of two or more condensed aromatic rings containing only carbon and hydrogen. PAHs were discovered at the beginning of the last century due to their carcinogenic effects. They are formed during incomplete combustion of all types of organic matter and are therefore present in a wide variety of emissions, ranging from natural biomass burning to the exhaust of all types of combustion engines (Finlayson-Pitts and Pitts, 1986). PAHs are present in both gas and particulate phases in the atmosphere, depending on the vapor pressure of each PAH, and can thus end up in the ground water and the soil. The simplest 2-ring PAH is naphthalene $\left(\mathrm{C}_{10} \mathrm{H}_{8}\right)$, which is the most volatile PAH and therefore present mainly in gas phase. While naphthalene itself is not carcinogenic, it is the most abundant PAH in polluted urban areas (Arey et al., 1989) and leads to formation of mutagenic nitronaphthalenes by $\mathrm{OH}$ and $\mathrm{NO}_{3}$-initiated reactions (Sasaki et al., 1997). The main sources of naphthalene in the urban atmosphere are motor vehicle exhaust and residential heating; the predominant sink is its reaction with $\mathrm{OH}$, leading to lifetimes of naphthalene typically shorter than one day (Atkinson and Arey, 1994).

PAHs in the atmosphere have been measured mostly by chromatographic techniques (e.g. Fraser et al., 1998; Cam et al., 2000; Williamson et al., 2002) and more recently by proton transfer reaction-mass spectrometry (PTR-MS) (Hewitt et al., 2003). Brandenburger et al. (1998) used differential optical absorption spectroscopy (DOAS) to measure atmospheric naphthalene in a rural area and found that its mixing ratio was between 2 and 16 parts per trillion by volume (pptv, $10^{-12}$ ). Here we present first measurements of atmospheric naphthalene by laser-induced fluorescence (LIF) in urban environments. Instrument calibrations are performed and fluorescence quenching of naphthalene is investigated in the laboratory.

\section{Experimental description}

The Penn State GTHOS/ATHOS (Ground-based/Airborne Tropospheric Hydrogen Oxides Sensor) was used to measure atmospheric naphthalene, along with $\mathrm{OH}$ and $\mathrm{HO}_{2}$ radicals. It is based on the Fluorescent Assay by Gas Expansion (FAGE) technique, which was originally developed by Hard et al. (1984). A detailed description of this instrument can be found in Faloona et al. (2004).

Correspondence to: $\mathrm{M}$. Martinez

(martinez@mpch-mainz.mpg.de) 

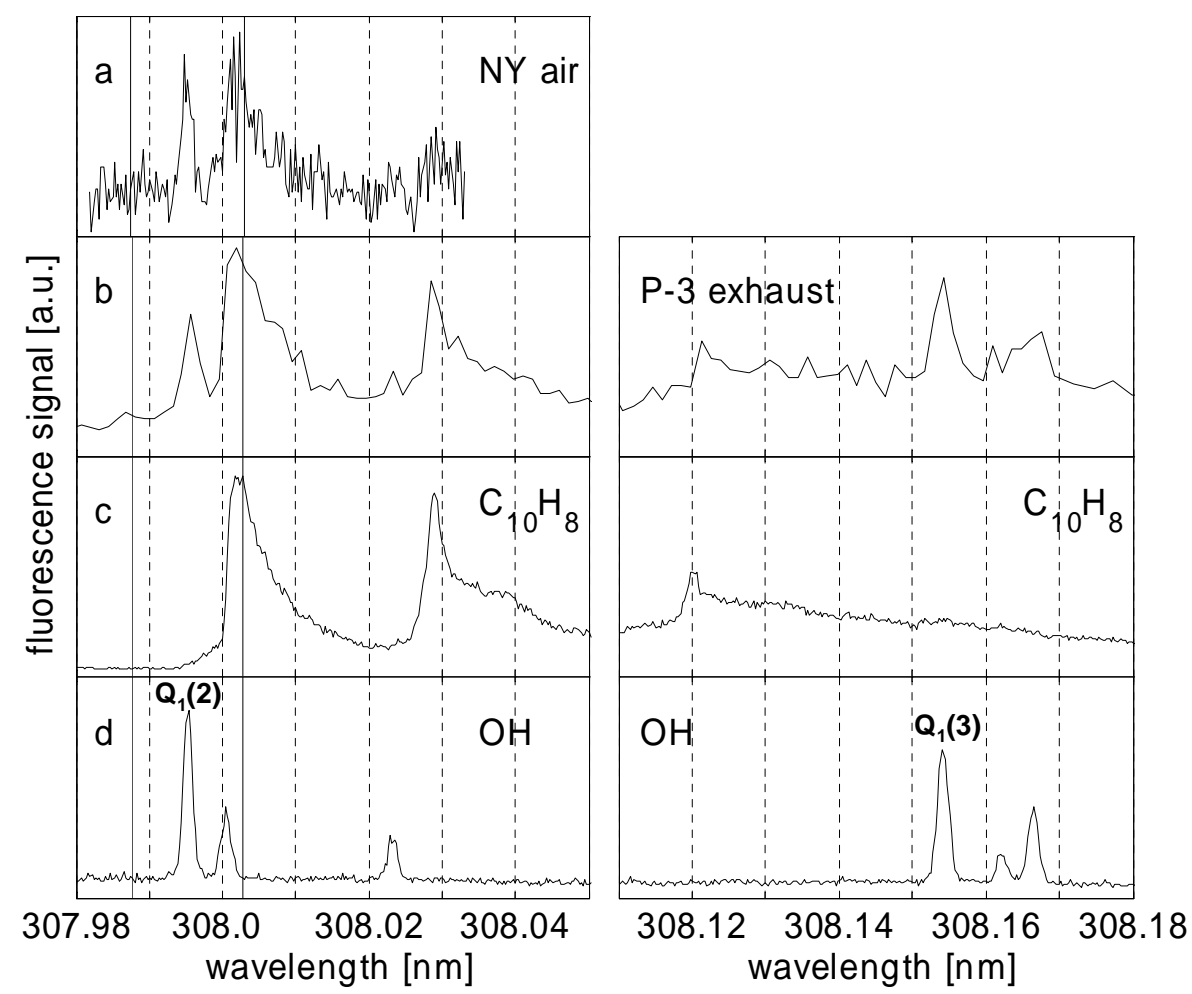

Fig. 1. Fluorescence spectra. Row (a): ambient air recorded in New York City; Row (b): ambient air recorded for wavelengths near the $\mathrm{Q}_{1}(2)$ and $\mathrm{Q}_{1}(3) \mathrm{OH}$ transitions at Kona airport while waiting for takeoff behind the NASA P-3 aircraft, sampling its exhaust; Row (c) and (d): naphthalene and the $\mathrm{OH}$ reference recorded in the laboratory for wavelengths near the $\mathrm{Q}_{1}(2)$ and $\mathrm{Q}_{1}(3) \mathrm{OH}$ transitions. The solid vertical lines indicate the wavelengths used for the offline measurements. The spectral resolution in row (b) is lower due to faster scanning.

The air sample expands through a pinhole inlet $(1 \mathrm{~mm}$ diameter) as it is pulled into a reduced pressure detection chamber by a vacuum pump. As the air flows through the laser beam, which passes 32 times through the detection volume in a White cell, the $\mathrm{OH}$ molecules are excited by spectrally narrow ( $\sim 4.7 \mathrm{GHz}$ FWHM) laser pulses ( $3 \mathrm{kHz}$ pulse repetition frequency) at one of several vibronic transition lines near $308 \mathrm{~nm}\left(\mathrm{~A}^{2} \Sigma v^{\prime}=0 \leftarrow \mathrm{X}^{2} \Pi v "=0\right)$. The UV laser beam is delivered to the detection module via a $0.20 \mathrm{~mm}$ diameter optical fiber (ThorLabs, Munich, Germany). The UV laser power entering the White cell is usually in the range of $2-12 \mathrm{~mW}$. The $\mathrm{OH}$ fluorescence extends beyond the prompt scattering (Rayleigh and wall scattering) and is detected with a microchannel plate detector (Hamamatsu, Hamamatsu City, Japan) that is switched into a high gain state after the lasergenerated scattering has ceased. The signal counter is also gated, and typically accepts counts from the detector for $\sim 300$ ns between its start and stop times.

For all measurements performed by our research group, the $\mathrm{Q}_{1}(2)$ vibronic transition line at $307.9951 \mathrm{~nm}$ (Dieke and Crosswhite, 1962) was used for $\mathrm{OH}$ measurements. The laser was tuned on and $\sim 0.0075 \mathrm{~nm}$ off resonance with the $\mathrm{OH}$ transition (called on-line and off-line) every $10 \mathrm{~s}$ to deter- mine respectively the $\mathrm{OH}$ fluorescence plus background signals and the background signals, resulting in a measurement time resolution of $20 \mathrm{~s}$. In order to be able to discern possible interferences from fluorescence of other trace gases, the offline background signals were recorded alternately at each side of the $\mathrm{OH}$ fluorescence wavelength. We have found that there is no significant interference for the instrument at the wavelength of the $\mathrm{OH} \mathrm{Q}_{1}(2)$ line (Ren et al., 2004). One of the two offline points, which has longer wavelength, was used to identify the naphthalene fluorescence, as described in Sect. 3.1.

Zero air with a constant naphthalene mixing ratio required for instrument calibration and other studies in the laboratory was produced by passing a constant flow of zero air through a drying tube filled with naphthalene and cooled to $0^{\circ} \mathrm{C}$. The naphthalene mixing ratio in this air flow is determined by the saturated vapor pressure of naphthalene, which is $0.763 \mathrm{~Pa}$ at $0^{\circ} \mathrm{C}$ (Wania et al., 1994). A flow rate of 30-300 standard cubic centimeters per minute $(\mathrm{sccm})$ of air containing this naphthalene vapor was then diluted with 13-40 standard liters per minute (slpm) of zero air to attain various mixing ratios of naphthalene and was supplied to the GTHOS inlet. 


\section{Results and discussion}

3.1 Spectrum identification of the naphthalene fluorescence

The background signals recorded with GTHOS/ATHOS at one side of the $\mathrm{OH}$ on-line wavelength were usually identical within the noise to the background signals recorded at the other side. Only occasionally, when measurements were conducted in highly polluted air, the background signals at the two offline wavelengths differed significantly. On these occasions the background signal at $308.0026 \mathrm{~nm}$, which in the following we will call the "red offline signal", was significantly higher than the background signal at $307.9876 \mathrm{~nm}$, in the following called the "blue offline signal", and sometimes even higher than the $\mathrm{OH}$ fluorescence signal when the atmospheric naphthalene mixing ratio was high.

Enhanced red offline signals appeared sporadically in our measurements in several field campaigns in urban environments. We therefore use only the blue offline signals for evaluation of the $\mathrm{OH}$ signals since we first detected the enhanced red offline signals in summer 1999. Field measurements in Nashville, TN, during the Southern Oxidant Study (SOS99), in Houston, TX, during the Texas Air Quality Study (TexAQS2000), and in New York City during the PM2.5 Technology Assessment and Characterization Study, New York (PMTACS-NY2001) sometimes showed these enhanced background signals during nighttime, when the boundary layer was shallow and stable enough to accumulate high levels of pollutants. We also observed the enhanced red offline signal occasionally when ATHOS was installed on the NASA DC-8 aircraft inside the NASA Dryden hangar, at Edwards Air Force Base, CA, in preparation for the Transport and Chemical Evaluation over the Pacific (TRACE-P) measurement campaign, especially when the motorized gangway was moved around the DC-8. During this campaign, a strongly enhanced red offline signal was further observed at the airport at Kona, Hawaii, while the DC-8 was waiting for takeoff on the runway right behind the NASA P-3 aircraft. On several occasions, the enhanced red offline signals were recorded at and near the airport of Hong Kong.

During TRACE-P in the Dryden hangar and at Kona, wavelength spectra of the fluorescence were recorded by tuning the ATHOS dye laser while the red offline signal was strongly enhanced. The spectra show several features in addition to the fluorescence lines of ambient $\mathrm{OH}$. The similarity of these features to the absorption lines of naphthalene as reported by Dorn et al. (1988) and by Neuroth et al. (1991) prompted us to measure naphthalene fluorescence spectra with GTHOS in the laboratory. Comparison of the spectra taken in the field and the naphthalene spectra taken in the laboratory strongly indicates that the enhanced red offline signal corresponds to the fluorescence of naphthalene (Fig. 1). As naphthalene is a constituent of petroleum and

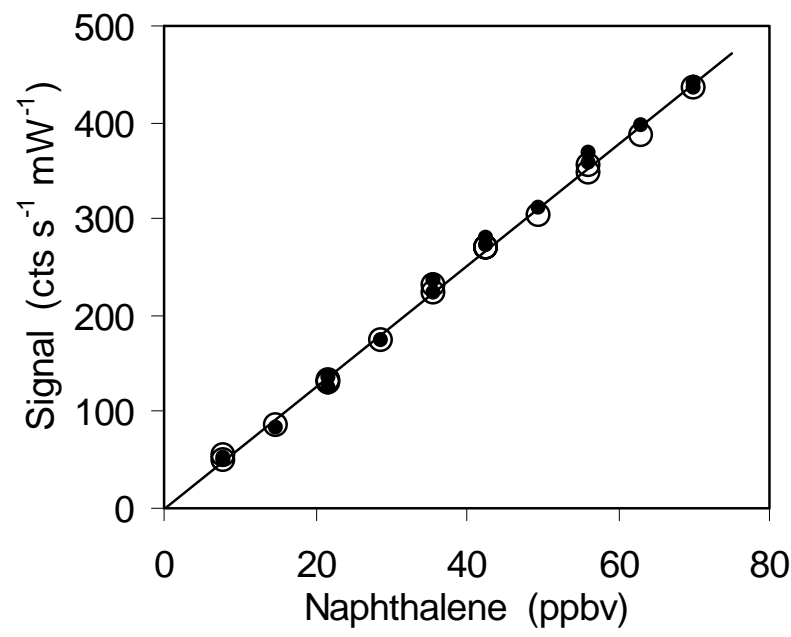

Fig. 2. Calibration of naphthalene LIF in dry zero air (solid circles) and in zero air containing about $2.5 \%$ water vapor (open circles). For dry air the sensitivity was $6.3 \pm 0.2 \mathrm{cts} \mathrm{s}^{-1} \mathrm{~mW}^{-1} \mathrm{ppbv}^{-1}$. The sensitivity in humid air of $6.2 \pm 0.1 \mathrm{cts} \mathrm{s}^{-1} \mathrm{~mW}^{-1} \mathrm{ppbv}^{-1}$ was the same within $1 \sigma$ error limits.

its refined products, it can be expected to appear in urban air polluted by traffic as well as in aircraft exhaust.

\subsection{Calibration}

The sensitivity of GTHOS/ATHOS for $\mathrm{OH}$ and naphthalene was determined in the laboratory for the different configurations used in several field missions and normalized to the $\mathrm{OH}$ sensitivities measured in the field. A detailed description of the $\mathrm{OH}$ calibration can be found in Faloona et al. (2004). For the naphthalene calibration, an air flow with various naphthalene mixing ratios between 5 and 80 parts per billion by volume (ppbv, $10^{-9}$ ) were supplied to the GTHOS inlet as described in Sect. 2. Calibrations show that the fluorescence signal is linear with naphthalene mixing ratio over this range (Fig. 2). The sensitivity was then calculated from the mean ratio of the signal normalized to laser power exiting the White cell and the mixing ratio. Table 1 summarizes the sensitivities and experimental conditions for the campaigns where we have observed naphthalene.

Water vapor reduces the sensitivity for $\mathrm{OH}$ by quenching the OH excited state molecules (Bailey et al., 1999). Therefore the sensitivity of our instrument for $\mathrm{OH}$ must be corrected for the effect of varying water vapor that is encountered in the field (Faloona et al., 2004). For naphthalene no significant reduction of the sensitivity was observed when water vapor mixing ratios of $2.5 \%$ were added to the zero air used as carrier gas (Fig. 2).

\subsection{Lifetime of the naphthalene fluorescence}

The lifetime of the naphthalene fluorescence was studied in the laboratory by narrowing the counter gate to $\sim 15 \mathrm{~ns}$ and 
Table 1. GTHOS/ATHOS sensitivities for naphthalene in zero air for different instrument configurations, characterized by pressure in the detection volume, power of the laser beam exiting the White cell, and the measurement start and stop times after the laser pulse exited the detection volume. The $1 \sigma$-uncertainties for the naphthalene sensitivities are about $20 \%$.

\begin{tabular}{lccccc}
\hline Mission & $\begin{array}{c}\text { Cell pressure } \\
(\mathrm{hPa})\end{array}$ & $\begin{array}{c}\text { Laser power } \\
(\mathrm{mW})\end{array}$ & $\begin{array}{c}t_{\text {start }}{ }^{a} \\
(\mathrm{~ns})\end{array}$ & $\begin{array}{c}t_{\text {stop }}{ }^{b} \\
(\mathrm{~ns})\end{array}$ & $\begin{array}{c}\mathrm{C}_{\left(\mathrm{C}_{10} \mathrm{H}_{8}\right)} \\
\left(\mathrm{cts} \mathrm{s}^{-1} \mathrm{~mW}^{-1} \mathrm{ppbv}^{-1}\right)\end{array}$ \\
\hline SOS99 & 2.8 & 2.4 & 220 & 520 & 3.2 \\
TexAQS2000 & 4.6 & 2.4 & 190 & 490 & 2.87 \\
TRACE-P & 11.6 & 10 & 100 & 612 & 2.15 \\
PMTACS-NY2001 & 4.7 & 5.0 & 180 & 692 & 10.25 \\
\hline
\end{tabular}

$a: t_{\text {start }}:$ start time of integration gate after the laser pulse exited the detection chamber.

$b$ : $\mathrm{t}_{\text {stop}}$ : stop time of integration gate after the laser pulse exited the detection chamber.

varying the period between the laser pulse and the start time of the counter gate. The fluorescence starts with the excitation of the fluorescing molecules and after that decays exponentially. The total decay rate, $\Gamma$, comprises the radiative decay rate, $\gamma_{\text {nat }}\left(1 / \gamma_{\text {nat }}\right.$ is the radiative lifetime), and the nonradiative decay of the excited state by collisional deactivation with nitrogen, oxygen, and water molecules, as described by the rate coefficients, $\mathrm{k}_{\mathrm{N}_{2}}, \mathrm{k}_{\mathrm{O}_{2}}$, and $\mathrm{k}_{\mathrm{H}_{2} \mathrm{O}}$, respectively. The quenching rate coefficients of $\mathrm{OH}$ and their temperature dependences have been determined by Bailey et al. (1997; 1999). The decay rate is related to the fluorescence intensity and can be expressed as

Intensity $=\left[\mathrm{OH}^{*}\right]_{\mathrm{o}} \exp (-\Gamma t)$

$\Gamma=\gamma_{\text {nat }}+k_{\mathrm{N}_{2}}(T)\left[\mathrm{N}_{2}\right]+k_{\mathrm{O}_{2}}(T)\left[\mathrm{O}_{2}\right]+k_{\mathrm{H}_{2} \mathrm{O}}(T)\left[\mathrm{H}_{2}\right]$,

where $\left[\mathrm{OH}^{*}\right]_{0}$ is the initial population of excited state $\mathrm{OH}\left(A^{2} \Sigma\right)$ established from the laser excitation, $t$ is time, [] denotes the number density of the enclosed chemical species, and the quenching rate coefficients have been written as functions of temperature, $T$, since their quenching efficiency increases at lower temperatures. The same equation can be applied to calculate the quenching of the naphthalene fluorescence.

We determined the radiative lifetime and the quenching rate coefficients for naphthalene at $297 \mathrm{~K}$, measured in the detection chamber by a thermistor, by studying the decay of the naphthalene fluorescence at different detection pressures and with pure nitrogen, pure oxygen and zero air as carrier gases. Figure 3a shows the fluorescence signal decay with time observed for $\mathrm{OH}$ and naphthalene in zero air at $4.5 \mathrm{hPa}$. The fluorescence lifetime measured for $\mathrm{OH}$ in $4.5 \mathrm{hPa}$ of air is $138 \pm 5 \mathrm{~ns}$, in good agreement with the fluorescence lifetime of $132 \pm 4 \mathrm{~ns}$ calculated from the quenching coefficients determined by Bailey et al. (1997) at $294 \mathrm{~K}$. The fluorescence lifetimes for naphthalene in $\mathrm{N}_{2}$ and $\mathrm{O}_{2}$ derived from exponential fits to the measured decays are plotted in Figs. $3 \mathrm{~b}$ and c.

The fluorescence lifetime of naphthalene decreases with pressure in both oxygen and nitrogen. The quench- ing rate coefficients, $\mathrm{k}_{\mathrm{N}_{2}}$ and $\mathrm{k}_{\mathrm{O}_{2}}$, can be calculated from Eq. (1) using the decay rates measured at pure nitrogen and pure oxygen, respectively, yielding $\mathrm{k}_{\mathrm{N}_{2}} \quad(297 \mathrm{~K})=(1.98 \pm 0.18) \times 10^{-11} \mathrm{~cm}^{3}$ molecule ${ }^{-1} \mathrm{~s}^{-1}$ and $\mathrm{k}_{\mathrm{O}_{2}}(297 \mathrm{~K})=(2.43 \pm 0.08) \times 10^{-10} \mathrm{~cm}^{3}$ molecule ${ }^{-1} \mathrm{~s}^{-1}$. Oxygen contributes more significantly to the quenching of naphthalene fluorescence than nitrogen by a factor of 12 . Collisions with water molecules do not deactivate excited naphthalene molecules significantly, as shown in Fig. 2. The upper limit for the quenching coefficient of naphthalene with water, $\mathrm{k}_{\mathrm{H}_{2} \mathrm{O}}$, as derived from the humid $\mathrm{N}_{2}$ and $\mathrm{O}_{2}$ lifetimes and their statistical uncertainties, is $\sim 1.3 \times 10^{-10} \mathrm{~cm}^{3}$ molecule ${ }^{-1} \mathrm{~s}^{-1}(297 \mathrm{~K})$. The sensitivity numbers in Table 1 would only decrease by about $3-6 \%$ if $\mathrm{k}_{\mathrm{H}_{2} \mathrm{O}}$ is equal to this upper limit at $\mathrm{H}_{2} \mathrm{O}$ mixing ratios of 1.5$3.5 \%$ measured during the campaigns. This is surprising as $\mathrm{OH}$ does quench effectively with water and may be due to the fact that naphthalene is a non-polar molecule. The radiative lifetimes calculated by extrapolating the decay rates in nitrogen and oxygen to $0 \mathrm{hPa}$ are in good agreement, yielding an average radiative lifetime of $340 \pm 10 \mathrm{~ns}$.

\subsection{Field measurements}

\subsubsection{SOS99}

We first observed naphthalene in the atmosphere during the SOS99 campaign, which took place in Nashville, TN, in summer 1999 . The detection limit, as given by the $2 \sigma$ noise of the 30-min averages of the naphthalene signal, was about 35 pptv during this campaign.

Enhanced naphthalene mixing ratios were usually observed during nights when the wind speed was low and high levels of pollutants were detected. Figure 4 shows the data collected during the campaign for naphthalene and $\mathrm{NO}_{\mathrm{x}}$ $\left(=\mathrm{NO}+\mathrm{NO}_{2}\right)$. Naphthalene correlated with pollutants such as $\mathrm{NO}_{x}$ and $\mathrm{CO}\left(\mathrm{r}^{2}=0.41\right.$ and 0.42 , respectively), and especially with hydrocarbons, which, like naphthalene, are predominantly emitted by fuel combustion, such as n-pentane and i-butanal $\left(\mathrm{r}^{2}=0.55\right.$ and 0.53 , respectively). 

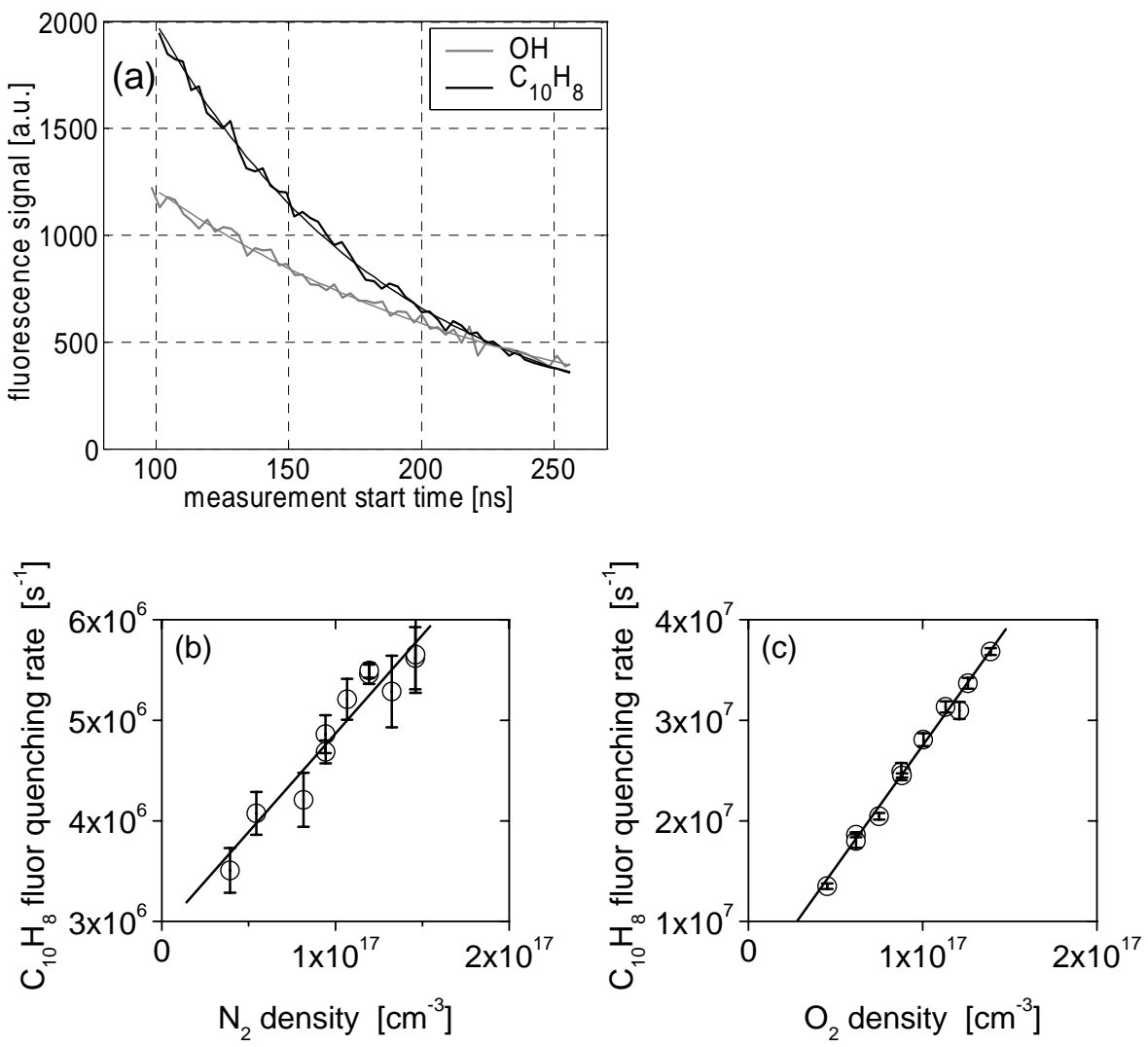

Fig. 3. Laboratory lifetime studies of naphthalene fluorescence. Panel (a): Variation of the fluorescence signal with time after excitation and simple exponential fits for $\mathrm{OH}$ (grey) and naphthalene (black) in $4.5 \mathrm{hPa}$ zero air. The fluorescence lifetimes derived from the exponential fits are $138 \pm 5 \mathrm{~ns}$ for $\mathrm{OH}$ and $90 \pm 2 \mathrm{~ns}$ for naphthalene. Panel (b): quenching rate of the naphthalene fluorescence as a function of nitrogen density, giving a least squares linear fit of $y=1.98 \times 10^{-11} \mathrm{x}+2.87 \times 10^{6}\left(\mathrm{r}^{2}=0.93\right)$. Panel (c): quenching rate of the naphthalene fluorescence as a function of oxygen density, giving a least squares linear fit of $y=2.43 \times 10^{-10} \mathrm{x}+3.00 \times 10^{6}\left(\mathrm{r}^{2}=0.99\right)$.

\subsubsection{TexAQS2000}

Naphthalene, along with $\mathrm{OH}$ and $\mathrm{HO}_{2}$, was measured as a part of the multi-investigator study TexAQS2000, which took place in Houston, Texas in August and September 2000 (Fig. 5).

We only occasionally observed naphthalene above detection limits, which were similar to Nashville. Like in Nashville, enhanced naphthalene mixing ratios in Houston were observed during nights with low wind speed and high pollutant concentrations, however wind speeds were generally higher than in Nashville. Due to the small number of occasions when naphthalene reached measurable values, correlation with other pollutants is poor $\left(\mathrm{R}^{2}=0.07\right.$ for $\mathrm{NO}_{\mathrm{x}}$ and 0.12 for $\mathrm{CO}$ ). However, the strong enhancement in naphthalene lasting for several hours in the early morning of 5 September (Julian day $=249$ ) coincided with CO levels of up to $900 \mathrm{ppbv}$, the highest measured during the campaign, and enhanced $\mathrm{NO}_{\mathrm{x}}$ of up to $60 \mathrm{ppbv}$.

\subsubsection{TRACE-P}

Highly polluted air was sampled in Hong Kong airport and sometimes during the last minutes before landing in Hong Kong. Naphthalene mixing ratios there were typically a few hundred pptv.

At Kona airport, while the DC-8 was waiting for takeoff on the runway right behind the NASA P-3 aircraft and thus sampling air strongly polluted by the P-3 exhaust, measured naphthalene mixing ratios reached 3 ppbv.

\subsubsection{PMTACS-NY2001}

Naphthalene was also measured during the PMTACS-NY field campaign, which took place in New York City in summer 2001. The optics and their arrangement were improved between TexAQS2000 and PMTACS-NY and the sensitivity in $\mathrm{OH}$ detection cell was increased (Table 1). The background-limited naphthalene detection limit was typically 6 pptv, for $2 \sigma$ confidence and a 10 -min integration 

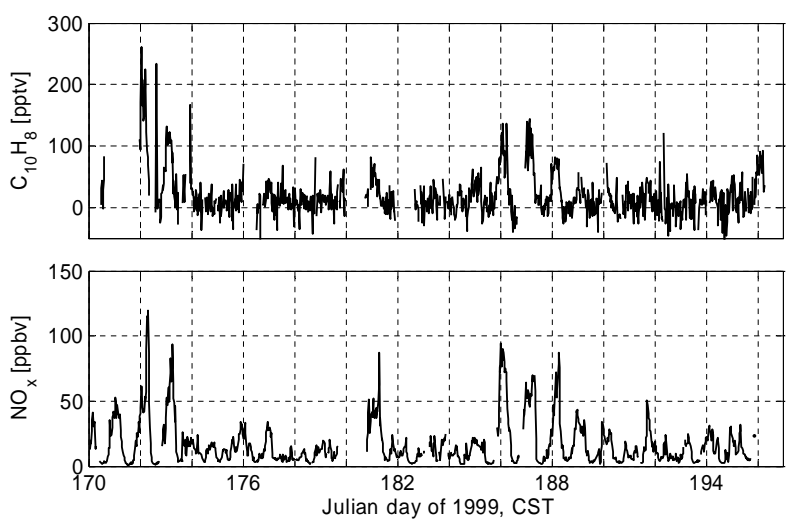

Fig. 4. Naphthalene and $\mathrm{NO}_{\mathrm{x}}$ mixing ratios measured in Nashville, TN, during SOS99, from 19 June to 16 July 1999.
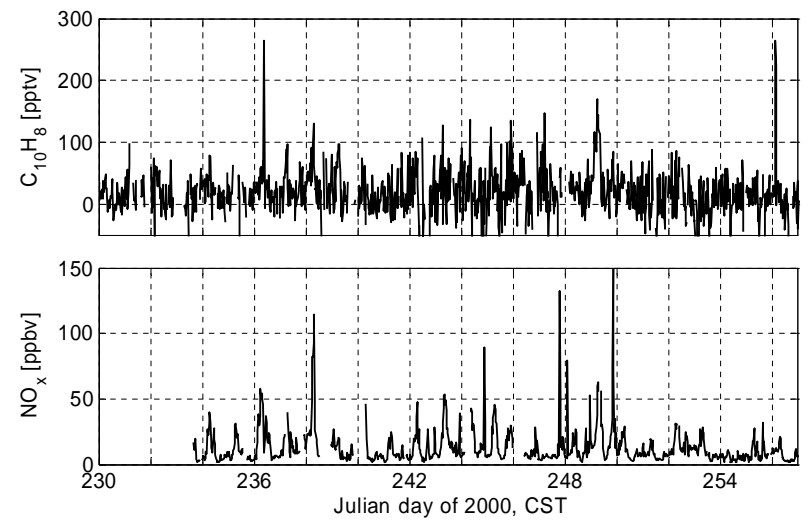

Fig. 5. Naphthalene and $\mathrm{NO}_{\mathrm{x}}$ mixing ratios measured in Houston, TX, during TexAQS2000, from 17 August to 16 September 2000.

time. Naphthalene was continuously measured for about one month from 30 June to 2 August 2001 (Fig. 6).

The typical diurnal variation of naphthalene had the maximum naphthalene appearing in the early morning, with an average mixing ratio up to about 40 pptv (Fig. 7), and the minimum naphthalene in the late afternoon, with an average mixing ratio of about $12 \mathrm{pptv}$. The day-to-day diurnal variation was large. The highest observed naphthalene mixing ratio was about $250 \mathrm{pptv}$, which was observed in the early morning of 21 July 2001 (Julian day=202) (Fig. 6). Naphthalene correlated very well with $\mathrm{NO}_{\mathrm{x}}\left(\mathrm{r}^{2}=0.56\right)$, indicating that both have the same sources, most likely vehicle exhaust. Good correlation was also found between naphthalene and $\mathrm{CO}\left(\mathrm{r}^{2}=0.56\right)$, and between naphthalene and total nonmethane hydrocarbons (NMHC) $\left(\mathrm{r}^{2}=0.46\right)$.

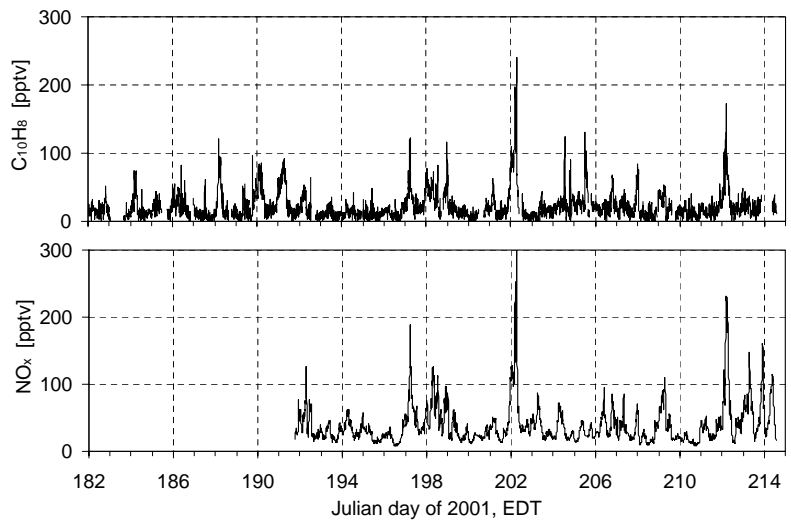

Fig. 6. Naphthalene and $\mathrm{NO}_{\mathrm{x}}$ mixing ratios in New York City, during the PMTACS-NY2001 campaign from 1 July to 3 August 2001.

\section{Conclusions}

We have established a new method for gas-phase naphthalene measurements in the atmosphere using laser-induced fluorescence technique at low pressure. The fluorescence spectrum of naphthalene near $308 \mathrm{~nm}$ is identified. Calibrations performed with a range of naphthalene mixing ratios between 5 and $80 \mathrm{ppbv}$ show that the fluorescence is linear with naphthalene mixing ratio over this range. The detection limit of the current GTHOS is 20 pptv for $2 \sigma$ uncertainty and 1-min integration, comparable to or better than other fast techniques, e.g. $\sim 12 \mathrm{pptv}$ for DOAS technique for $2 \sigma$ confidence and a 200-s integration (Brandenburger et al., 1998) and $\sim 100$ pptv for PTR-MS technique for $2 \sigma$ confidence and a $40-\mathrm{s}$ integration (M. Alexander, personal communication, 2003). Naphthalene fluorescence quenching by $\mathrm{O}_{2}, \mathrm{~N}_{2}$ and $\mathrm{H}_{2} \mathrm{O}$ was studied. Quenching rate coefficients of $\mathrm{N}_{2}$ and $\mathrm{O}_{2}$ were measured to be $\mathrm{k}_{\mathrm{N}_{2}}$ $(297 \mathrm{~K})=(1.98 \pm 0.18) \times 10^{-11} \mathrm{~cm}^{3}$ molecule $\mathrm{e}^{-1} \mathrm{~s}^{-1}$ and $\mathrm{k}_{\mathrm{O}_{2}}$ $(297 \mathrm{~K})=(2.43 \pm 0.08) \times 10^{-10} \mathrm{~cm}^{3}$ molecule $\mathrm{e}^{-1} \mathrm{~s}^{-1}$ while the upper limit for the quenching rate coefficient for $\mathrm{H}_{2} \mathrm{O}$ is $1.3 \times 10^{-10} \mathrm{~cm}^{3}$ molecule ${ }^{-1} \mathrm{~s}^{-1}$ at $297 \mathrm{~K}$, which has insignificant effect on the sensitivity of LIF for detecting naphthalene in the ambient air. Atmospheric naphthalene mixing ratios have been measured at three urban sites, Nashville, TN, Houston, TX, and New York City, NY, and good correlation between naphthalene and several pollutants that are predominantly emitted by fuel combustion is found.

It is in principle possible to measure other monocyclic and polycyclic aromatic hydrocarbons with this technique. Any species absorbing in the UV without photodissociating is likely to fluoresce and should therefore be detectable with LIF. 


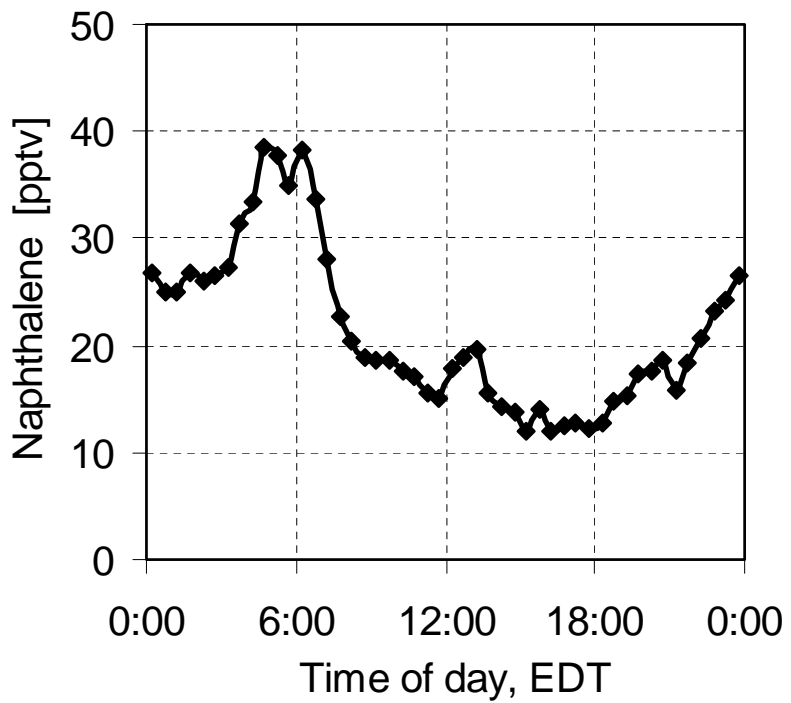

Fig. 7. Average diurnal profile of naphthalene in $30 \mathrm{~min}$ intervals.

Acknowledgements. This work is supported by grants primarily from NSF (ATM-9974335), and NOAA (40RANR901074 and 40RANROM1560) for the measurements in Nashville and Houston, and from the U.S. EPA through State University of New York at Albany (cooperative agreement \# R828060010) for the measurements in New York City. The authors thank the science teams who participated in these campaigns, and especially E. J. Williams, C. A. Stroud, and J. J. Schwab for providing the $\mathrm{NO}_{x}$ and hydrocarbon data used in this work.

Edited by: L. Carpenter

\section{References}

Arey, J., Atkinson, R., Zielinska, B., and McElroy, P. A.: Diurnal concentrations of volatile polycyclic aromatic hydrocarbons and nitroarenes during a photochemical air pollution episode in Glendora, California, Environ. Sci. Technol., 23, 321-327, 1989.

Atkinson, R. and Arey, J.: Atmospheric chemistry and gas-phase polycyclic aromatic hydrocarbons: formation of atmospheric mutagens, Environ. Health Perspect., 102, Suppl. 4, 117-126, 1994.

Bailey, A. E., Heard, D. E., Paul, P. H., and Pilling, M. J.: Collisional quenching of $\mathrm{OH}\left(\mathrm{A}^{2} \Sigma^{+}\right.$, v'=0) by $\mathrm{N}_{2}, \mathrm{O}_{2}$, and $\mathrm{CO}_{2}$ between 204 and $294 \mathrm{~K}$. Implications for atmospheric measurements of $\mathrm{OH}$ by laser-induced fluorescence, J. Chem. Soc., Faraday Trans., 93, 2915-2920, 1997.

Bailey, A. E., Heard, D. E., Henderson, D. A., and Paul, P. H.: Collisional quenching of $\mathrm{OH}\left(\mathrm{A}^{2} \Sigma^{+}, \mathrm{v}^{\prime}=0\right)$ by $\mathrm{H}_{2} \mathrm{O}$ between 211 and $294 \mathrm{~K}$ and the development of a unified model for quenching, Chem. Phys. Lett., 302, 132-138, 1999.
Brandenburger, U., Brauers, T., Dorn, H.-P., Hausmann, M., and Ehhalt D. H.: In-situ measurements of tropospheric hydroxyl radicals by folded long-path laser absorption during the field campaign POPCORN, J. Atmos. Chem., 31, 181-204, 1998.

Cam, D., Gagni, S., Meldolesi, L., and Galletti, G.: Determination of polycyclic aromatic hydrocarbons in sediment using solidphase microextraction with gas chromatography mass spectrometry, J. Chromatogr. Sci., 38, 55-60, 2000.

Dieke, G. H. and Crosswhite H. M.: The ultraviolet bands of OH, J. Quant. Spectr. Rad. Trans., 2, 97-111, 1962.

Dorn, H.-P., Callies, J., Platt, U., and Ehhalt, D. H.: Measurement of tropospheric $\mathrm{OH}$ concentrations by laser long-path absorption spectroscopy, Tellus, 437-445, 1988.

Faloona, I. C., Tan, D., Lesher, R. L., Hazen, N. L., Frame, C. L., Simpas, J. B., Harder, H., Martinez, M., DiCarlo, P., Ren, X., and Brune, W. H.: A laser induced fluorescence instrument for detecting tropospheric $\mathrm{OH}$ and $\mathrm{HO}_{2}$ : Characteristics and calibration, J. Atmos. Chem., 47, 139-167, 2004.

Finlayson-Pitts, B. J. and Pitts, J. N.: Atmospheric Chemistry: Fundamentals and experimental techniques, John Wiley \& Sons, New York, 1986.

Fraser, M. P., Cass, G. R., Simoneit, B. R. T., and Rasmussen, R. A.: Air quality model evaluation data for organics. 5. $\mathrm{C}_{6}-\mathrm{C}_{22}$ nonpolar and semipolar aromatic compounds, Environ. Sci. Technol., 32, 1760-1770, 1998.

Hard, T. M., O'Brien, R. J., Chan, C. Y., and Mehrabzadeh A. A.: Tropospheric free radical determination by FAGE, Environ. Sci. Technol., 18, 768-777, 1984.

Hewitt, C. N., Hayward, S., and Tani, A.: The application of proton transfer reaction-mass spectrometry (PTR-MS) to the monitoring and analysis of volatile organic compounds in the atmosphere, J. Environ. Monit., 5, 1-7, 2003.

Neuroth, R., Dorn, H. -P., and Platt, U.: High resolution spectral features of a series of aromatic hydrocarbons and BrO: Potential interferences in the atmospheric $\mathrm{OH}-$ measurements, J. Atmos. Chem., 12, 278-298, 1991.

Ren, X., Harder, H., Martinez, M., Faloona, I., Tan, D., Lesher, R. L., DiCarlo, P., Simpas, J. B., and Brune, W. H.: Interference testing for atmospheric $\mathrm{HO}_{\mathrm{x}}$ measurements by laser-induced fluorescence, J. Atmos. Chem., 47, 169-190, 2004.

Sasaki, J., Aschmann, S. M., Kwok, E. S. C., Atkinson, R., and Arey, J.: Products of the gas-phase $\mathrm{OH}$ and $\mathrm{NO}_{3}$ radical-initiated reactions of naphthalene, Environ. Sci. Technol., 31, 3173-3179, 1997.

Stevens, P. S., Mather, J. H., and Brune, W. H.: Measurement of tropospheric $\mathrm{OH}$ and $\mathrm{HO}_{2}$ by laser-induced fluorescence at low pressure, J. Geophys. Res., 99(D2), 3543-3557, 1994

Wania, F., Ahiu, W. -Y., and Mackay, D.: Measurement of the vapor pressure of several low-volatility organochlorine chemicals at low temperatures with a gas saturation method, J. Chem. Eng. Data, 39, 572-577, 1994.

Williamson, K. S., Petty, J. D., Huckins, J. N., Lebo, J. A., and Kaiser, E. M.: HPLC-PFD determination of priority pollutant PAHs in water, sediment, and semipermeable membrane devices, Chemosphere, 49, 703-715, 2002. 